\title{
Nursing Informatics Research and Emerging Trends in 2015
}

Jane M. Carrington

University of Arizona

Victoria Tiase

Nicolette Estrada

University of Arizona

Kimberly D. Shea

University of Arizona

Katherine M. Dudding

University of Arizona

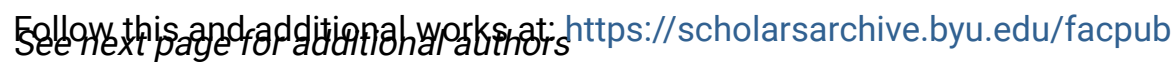

Part of the Other Nursing Commons

\section{Original Publication Citation}

Carrington, J. M., Tiase, V., Estrada, N., Shea, K. D., Dudding, K. M., Finley, B. A., Nibbelink, C., Rasmussen, R. J., Roberts, M. L. (2016). Nursing Informatics Research and Emerging Trends in 2015. CIN: Computers, Informatics, Nursing, 34(7), 284-286.

\section{BYU ScholarsArchive Citation}

Carrington, Jane M.; Tiase, Victoria; Estrada, Nicolette; Shea, Kimberly D.; Dudding, Katherine M.; Finley, Brooke A.; Nibbelink, Christine; Rasmussen, Ryan Jay; and Roberts, Monte L., "Nursing Informatics Research and Emerging Trends in 2015" (2016). Faculty Publications. 5318.

https://scholarsarchive.byu.edu/facpub/5318 accepted for inclusion in Faculty Publications by an authorized administrator of BYU ScholarsArchive. For more information, please contact ellen_amatangelo@byu.edu. 


\section{Authors}

Jane M. Carrington, Victoria Tiase, Nicolette Estrada, Kimberly D. Shea, Katherine M. Dudding, Brooke A. Finley, Christine Nibbelink, Ryan Jay Rasmussen, and Monte L. Roberts 


\section{Nursing Informatics Research and Emerging Trends in 2015}

Jane M. Carrington, PhD, RN, Victoria Tiase, MSN, RN-BC, Nicolette Estrada, PhD, RN, Kimberly D. Shea, PhD, RN, Katherine M. Dudding, RN, Brooke A. Finley, BSN, RN, Christine Nibbelink, MS, RN, Ryan J. Rasmussen, MSN, FNP-BC, Monte L. Roberts, DNP, RN

T his article presents the annual project where we search the literature to learn the advances made in nursing informatics research. The Nursing Informatics Year in Review project originated with the American Medical Informatics Association (AMIA)-Nursing Informatics Work Group (NIWG) as a regular presentation at the AMIA-NIWG Sunday meeting. This article reports on the findings from project year four, 2015, that was presented at the AMIA-NIWG meeting in San Francisco, CA, in November 2015. As with prior years of this project, we have read articles that have contributed to further development of the science. This article presents the results from our systematic review of the nursing informatics literature and the emerging trends.

Nursing informatics research is well into its fourth decade yet remains a young specialty. In 1986, Schwirian ${ }^{1}$ characterized the volume of nursing research as "sparse" and in need of focus, direction, and cumulative properties. Since 1986, nursing informatics research has advanced in number of publications and has demonstrated its value as a science generating knowledge about nursing and technology. As nursing informatics has grown from infancy, we now have the opportunity to quantitatively examine trends and identify future areas for research. Effken ${ }^{2}$ identified the lack of overarching models or theories guiding nursing informatics research that has made it difficult to identify concepts that can be used broadly to develop the science of nursing informatics. Later, Bakken and colleagues ${ }^{3}$ noted that a nursing informatics research agenda for 2008 to 2018 must reflect changes in context, notably, genomic healthcare, shifting research paradigms, and social technologies. ${ }^{3}$ Both of these works were incorporated while examining this evolving field of nursing research.

The purposes of this article are to report the findings from a literature review of nursing informatics research and highlight

Author Affiliations: College of Nursing, University of Arizona, Tucson (Drs Carrington, Estrada, Shea, and Roberts; and Ms Dudding, Finley, and Nibbelink; and Mr Rasmussen); and New YorkPresbyterian Hospital, New York City (Ms Tiase).

Portions of this article were presented at the American Medical Informatics Association-Nursing Informatics Work Group Sunday Special Event, November 2015, San Francisco, CA.

The authors have disclosed that they have no significant relationships with, or financial interest in, any commercial companies pertaining to this article.

Corresponding author: Jane M. Carrington, PhD, RN, College of Nursing, University of Arizona, 1305 N Martin, Tucson, AZ 85721-0203 (jcarrington@nursing.arizona.edu).
KEY POINTS:

- Nursing informatics research continues to grow as the specialty matures.

- Research in acute care settings was most common, followed by nursing education.

- A wide variety of research designs are represented with many qualitative studies; randomized controlled trials are uncommon.

articles that were recommended by AMIA-NIWG members as having influenced their work. This project sought to explore nursing informatics research for the last year. In so doing, we (1) quantified the number of nursing informatics research papers in the last year, (2) identified topics and themes of nursing informatics research, and (3) solicited influential works from nursing informatics colleagues.

\section{METHODS}

Consistent with prior years of this project, a two-phase approach was used. The first phase was a literature review using key words "informatics" and "nursing informatics" in the following search databases: PubMed, AcademicOne, CINAHL, and ScienceDirect. Inclusion criteria included research papers published in peer-reviewed journals between August 1, 2014, and August 1, 2015, with an RN as the first author; this was determined by an Internet search if not included in the authorship of the article. In phase 2, key articles from AMIA-NIWG members were solicited on the basis of being influential in members' thinking and research. For inclusion, these articles had to meet the same criteria described in phase 1 .

\section{RESULTS}

\section{Phase 1}

The initial search resulted in a total of 46 articles. Of these, 38 articles met criteria for inclusion (Table 1). These articles were analyzed to determine journal of publication frequency, research methods used, research setting, and area of focus. Publications were identified most frequently in Nurse Education Today ( $\mathrm{n}=5)$, International Fournal of Medical Information $(\mathrm{n}=4)$, Fournal of American Medical Informatics Association ( $\mathrm{n}=3)$ and MedInfo2015 ( $\mathrm{n}=3)$. 
Table 1. Results of Database Literature Search

\begin{tabular}{|l|c|c|}
\hline Databases & Initial Search Results & Articles That Met Criteria \\
\hline AcademicOne & 5 & 5 \\
\hline CINAHL & 2 & 2 \\
\hline PubMed & 29 & 21 \\
\hline ScienceDirect & 22 & 18 \\
\hline Total & 46 & 38 \\
\hline
\end{tabular}

Research methods used by researchers included qualitative, quantitative, literature review, descriptive, intervention, and mixed methods. Qualitative methods were most frequently used $(\mathrm{n}=14)$, followed by literature review $(\mathrm{n}=8)$, quantitative $(n=5)$, intervention $(n=4)$, and mixed methods $(n=2)$.

The research setting and area of focus aligned with hospitals being the most common setting $(\mathrm{n}=17)$ and electronic health record/clinical systems $(\mathrm{n}=13)$ being the most common area of research focus. Education was the next most frequent setting $(\mathrm{n}=10)$, and there were eight articles in which education was the focus. Outpatient $(n=7)$ and public health $(n=6)$ were the next most frequent research settings with mobile/electronic health or e-Health as an area of focus $(\mathrm{n}=7)$.

\section{Phase 2}

The second part of this project was the analysis of articles recommended by members of the AMIA-NIWG that informed members' thinking and scholarship. For inclusion, recommended articles had to meet the same criteria as those listed previously and include selection rationale. The committee received 12 recommended articles; eight met the established criteria. Bouyer-Ferullo et $\mathrm{al}^{4}$ described a project involving operating room nurses and the implementation of a basic decision support screen that identified patients at risk for peripheral nerve injury. This article was recommended because of its impact upon increasing patient safety by reducing injury risk and including a reminder for nurses to communicate their interventions to reduce peripheral nerve injury. Bouyer-Ferullo and colleagues ${ }^{4}$ reported that peripheral nerve injury documentation rates increased from $63 \%$ to $92 \%$ and missing documentation rates decreased from $26 \%$ to $19 \%$.

The article by Alexander et $\mathrm{al}^{5}$ was recognized because the findings revealed that additional technological and human resources were needed to build a health information technology network in 16 long-term care facilities in the sample. This conclusion was supported by surveys, observations, and interviews that improved understanding on lack of preparation implementing health information exchange in long-term care facilities.

Alexander ${ }^{6}$ was recommended because this qualitative research study increased understanding of the strategies nursing assistants use to communicate pressure ulcer prevention practices in long-term care facilities. Strategies differed in accordance with the sophistication level of used information technology. Specific themes that arose from focus groups included "passing on information," "keeping track of needs," and "information access." Additional results included the findings that patient records in long-term care are incomplete and do not accurately reflect the work of the nursing assistants. ${ }^{6}$

Harris et $\mathrm{al}^{7}$ wrote an article addressing an existing gap in the literature by demonstrating the feasibility and value of a "bottom-up" approach to developing the common model and sets of terms that are the cornerstone of semantic interoperability. The purpose of the research by Harris and colleagues ${ }^{7}$ was to harmonize and extend standards by leveraging the knowledge within local documentation artifacts that are not well described. The researchers used nurse flowsheets from six large healthcare organizations for analysis, and results were then used for model development.

A literature review by Irizarry et $\mathrm{al}^{8}$ was recommended because the article added to the body of work building knowledge in the area of patient portal development from a patientcentric viewpoint by presenting the state of the science on patient engagement using patient portals. Results suggest that patient adoption, provider endorsement, health literacy, usability, and utility are key factors for patient portal adoption.

The article authored by Moss and Berner ${ }^{9}$ was recommended as it is one of few studies in medication decision support for nurses. Seeking to reduce medication administration errors, the authors sought to develop a method and tools for the design of clinical decision support systems specific to medication administration. ${ }^{9}$ Performed in simulation, Moss and Berner ${ }^{9}$ used a mixed methods approach, learned that nurses underestimate their need for support, and found that brief, color-coded, and easily accessible alerts were preferred.

Sockolow et al $^{10}$ assessed a health information technology reference-based evaluation framework in both the hospital and home care settings. Using interviews and surveys, Sockolow and colleagues ${ }^{10}$ concluded that home health clinicians were satisfied with hardware availability. Acute care nurses preferred electronic documentation rather than paper. Nurses in both settings were dissatisfied with ongoing training, software usability, and functionality. The article was recommended because of its comprehensive approach in examining the health information technology reference-based evaluation framework.

Staggers et $\mathrm{al}^{11}$ reported on current usability problems in electronic medication administration records (eMARs) and bar code medication administration systems and sought to determine how these might affect nurses' situational awareness. Results revealed 99 usability problems emerged, and, of these, 15 are considered catastrophic, 35 are considered major, 48 are considered minor, and 1 is considered cosmetic. ${ }^{11}$ The article was recommended on the basis of its 
comprehensive eMAR evaluation, which revealed significant issues with eMAR usability in practice.

\section{DISCUSSION}

This article describes the results from the fourth year of the Nursing Informatics Year in Review project. Having used a consistent methodology throughout, trends have emerged from year to year in nursing informatics research. For example, in the initial years of the project, academia was the most common setting for nursing informatics research. ${ }^{12}$ The most common setting for nursing informatics research in 2015 was acute care, with electronic health record (EHR) and clinical systems as the most common areas of focus. Outpatient and public health/community emerged as the third and fourth most common research settings, and mobile/e-Health emerged as the third most common area of focus. In project year 3, the research setting of public health was represented by three articles, and two articles reported on work with mobile technology. ${ }^{13}$

Research methods used in nursing informatics have varied little from project year 3 to project year 4 . Researchers in the field of nursing informatics commonly use qualitative research methods. The frequency of literature reviews increased this project year from last year, with three articles in 2014 and eight articles in 2015. ${ }^{13}$ The frequency of descriptive studies increased only slightly this year, from four articles in 2014 to six articles in 2015. ${ }^{13}$

The number of recommended articles decreased this year, from 33 in project year 3 to eight in this project year. Recommended articles ranged in setting from the operating room, healthcare organizations, acute care, long-term care, home, literature, and simulation laboratory and represented a range of research methods: qualitative, quantitative, model development and testing, and mixed methods. These articles represent outstanding work leading to increasing patient outcomes using technology across settings and patient populations.

\section{Limitations}

The selected search terms and inclusion criteria may have eliminated excellent work in nursing informatics. The work described in this article is not comprehensive of all published work this past year by nursing informatics scientists. Two project design elements resulted in an incomplete list of outstanding nursing informatics research from 2015. First, is it possible that not all authors use the explicit terms as keywords in their articles. Since authors may use terms more specific to the domains of the study and not include the general terms we used in our search, many articles were not included in our analysis. The goal of the project is to review the broad science of nursing informatics, without attempting to capture all the specific domains. Second, use of the nurse as the first author in the search may have eliminated team science articles in which the nurse, in a more senior role, was listed as the last author. The rationale for use of the nurse as the first author criteria is based on the AMIA-NIWG Harriet Werley Award presented annually at the AMIA meeting, which acknowledges outstanding research in which the first author is a nurse.

\section{CONCLUSIONS}

This article reports findings of the fourth project year of the Nursing Informatics Year in Review. Within author-identified nursing informatics studies, education remains a setting and focus of nursing informatics research, along with acute care and EHR/clinical systems. Perhaps, a new emerging trend in nursing informatics research is public health/community setting and mobile/e-Health-focused research. Research methods used are a spectrum of methods, with qualitative research being the most frequent. The predominance of qualitative research methods in nursing informatics research is consistent with the early stages of the specialty and the need to describe the meaning and integration of new technologies for patient care. The ongoing project provides a mechanism to reveal the work done by nursing informatics scientists in an attempt to add focus and direction in cumulative efforts to improve patient care.

\section{References}

1. Schwirian PM. The NI pyramid-a model for research in nursing informatics. Comput Nurs. 1986;4(3): 134-136.

2. Effken JA. An organizing framework for nursing informatics research. Comput Inform Nurs. 2003;21(6): 316-323.

3. Bakken S, Stone PW, Larson EL. A nursing informatics research agenda for 2008-18: contextual influences and key components. 2008. Nurs Outlook. 2012;60(5): 280.e3-288.e3.

4. Bouyer-Ferullo S, Androwich IM, Dykes PC. Clinical decision support and perioperative peripheral nerve injury: a quality improvement project. Comput Inform Nurs. 2015;33(6): 238-248.

5. Alexander GL, Rantz M, Galambos C, et al. Preparing nursing homes for the future of health information exchange. Appl Clin Inform. 2015;6(2): 248-266.

6. Alexander GL. Nurse assistant communication strategies about pressure ulcers in nursing homes. West J Nurs Res. 2015;37(7): 984-1004.

7. Harris MR, Langford LH, Miller H, Hook M, Dykes PC, Matney SA. Harmonizing and extending standards from a domain-specific and bottom-up approach: an example from development through use in clinical applications. J Am Med Inform Assoc. 2015;22(3): 545-552.

8. Irizarry T, DeVito Dabbs A, Curran CR. Patient portals and patient engagement: a state of the science review. J Med Internet Res. 2015;17(6): e148.

9. Moss J, Berner ES. Evaluating clinical decision support tools for medication administration safety in a simulated environment. Int J Med Inform. 2015;84(5): 308-318.

10. Sockolow PS, Bowles KH, Rogers M. Health Information Technology Evaluation Framework (HITREF) comprehensiveness as assessed in electronic point-of-care documentation systems evaluations. In: Sarkar IN, ed. 15th World Congress on Health and Biomedical Informatics. Sao Paulo, Brazil: Medinfo; 2015: 19-23.

11. Staggers N, Iribarren S, Guo JW, Weir C. Evaluation of a BCMA's electronic medication administration record. West J Nurs Res. 2015;37(7): 899-921.

12. Carrington JM, Tiase VL, Estrada N, Shea KD. Nursing education focus of nursing informatics research in 2013. Nurs Adm Q. 2014;38(2): 189-191.

13. Carrington JM, Tiase VL, Estrada N, Shea KD. Research in nursing informatics 2014. Nurs Adm Q. 2015;39(2): E9-E16. 